\title{
Common Pilot Channel Power Control for UMTS Cellular Networks Traffic Load Balancing based on Fuzzy Logic Control
}

\author{
Jane M. Mutua \\ Department of Telecommunication \\ Engineering \\ PAUSTI \\ Nairobi, Kenya
}

\author{
George N. Nyakoe \\ Department of Telecommunication and \\ Information Systems \\ JKUAT \\ Nairobi, Kenya
}

\author{
Vitalice K. Oduol \\ Department of Electrical and \\ Information Engineering \\ University of Nairobi (UoN), \\ Nairobi, Kenya
}

\begin{abstract}
Network congestion control remains important and of high priority, especially given the growing size, demand, and speed of cellular networks. Recent research in this area has come up with Capacity and Coverage Optimization techniques based on Self Organizing Networks (SONs). A major issue tackled by SONs is the irregular and frequently changing distribution of cellular subscribers both in time and area. As existing network technologies continue to evolve, more and more tunable parameters and various customizations are being introduced. This has resulted in a rise in complexity that is making traditional manual optimization challenging. On the other hand, even though current Self-Organizing Networks (SON) focus is on Long Term Evolution (LTE) and beyond, legacy networks such as 3G are adopting different SON based solutions to address the above mentioned challenges in other radio access network (RAN) types.

In this paper the problem of capacity optimization in 3G Cellular Networks is addressed using Rule-Based Fuzzy Logic to control the CPICH power and as a result improve the cell capacity. One of the reasons for choosing Fuzzy Logic Controllers (FLC) is its logical resemblance to a human operator. It operates on the foundations of a knowledge base derived from an expert operator's knowledge. The autonomous operation is aimed at reducing the frequent attention and effort required by a radio optimization engineer to carry out capacity optimization tasks which are currently done mostly manually. The FLC will be involved in the detection of high load $3 G$ cells that do not have enough cell resources available and could benefit from $\mathrm{CPICH}$ power adjustment as a radio optimization engineer would normally do manually. Simulation results show that the CPICH power control system based on fuzzy achieves a significant improvement in the Downlink cell utilization which in turn improves the cell performance compared to a constant CPICH power system.
\end{abstract}

Keywords-Capacity, Common Pilot Channel (CPICH), Fuzzy Logic, Wideband Code Division Multiple Access (WCDMA);

\section{INTRODUCTION}

Network congestion control remains important and of high priority, especially given the accelerated growth in size and demand of cellular networks [1]. This is where the need for an intelligent capacity optimization algorithm becomes apparent. The 3G network Wideband Code Division Multiple Access (WCDMA) system is a self-interfering system. As the Network load increases, the interference rises thereby negatively impacting the quality of service and the coverage of cells. Therefore, the capacity, coverage, and quality of service of the
WCDMA system are mutually dependent [2]. In other words, when one of these factors undergoes a change, the other factors are affected. The operator can trade quality against cj3overage, capacity against quality, but the amount of resources does not change, it is only redistributed. For example, to extend the coverage of a cell, it is required to either offer less capacity or decrease the quality requirements, or both. In order to increase the capacity, it is necessary to shrink the coverage or decrease the quality requirements, or both.

\section{A. Capacity Planning}

Capacity Planning is essential in wideband code division multiple access (WCDMA) radio access networks (RAN) so as to evaluate the optimal site configuration in terms of pilot and common control channel powers, throughput, and the soft handover parameter [3],[4]. The objective for capacity planning is to support the subscriber traffic with acceptable low blocking and latency. The capacity of a cell affects the coverage of the cell. The cell breathes as the amount of users varies. To keep the quality of services in suitable levels, admission control, packet scheduling, and handover mechanisms are used. The importance of capacity increases when the network expands and the amount of traffic grows. Each cell should be loaded relatively equally and in a way that there is room for future growth. Automated optimization algorithms are required to perform the radio network optimization process quickly and efficiently, with minimal cost, time and effort contribution [2].

The cell capacity requires frequent attention by the radio optimization engineer due to the constantly shifting traffic patterns as subscribers are added to the network [5]. Specific considerations for capacity optimization include difference in the capacity requirements between peak and off-peak hours of the day. Therefore, this requires more frequent changes in the network, e.g. several times a day to address moving patterns and varying user concentrations, and are quite complex as they require learning and pattern recognition algorithms. Due to the complexity and expense of optimizing network coverage and capacity manually, particularly as network operations and performance management for data networks such as $3 \mathrm{G}$ get cumbersome, fuzzy logic is a good candidate for automated processing because of its logical resemblance to a human operator [6].

\section{B. Network Parameters}

There exist numerous configurable base station parameters that the network operator can modify to influence the coverage and 
capacity for example antenna settings such as azimuth, height and tilt, $\mathrm{CPICH}$ power and handover parameters [7].

\section{1) Common Pilot Channel Power Control}

In radio access networks (RAN) using wideband code division multiple access (WCDMA), the common pilot channel $(\mathrm{CPICH})$ is used by the user equipment for channel quality estimation, cell selection, and handover [1]. The $\mathrm{CPICH}$ signal strength determines the coverage area of the cell, affects the cell capacity, and in addition the quality of service, and is therefore a crucial parameter in radio network planning and optimization [5]. The CPICH pilot power allows for control of the strength of the $\mathrm{CPICH}$ signal such that the more power is set for the pilot signals, the better coverage is obtained. The optimal setting of $\mathrm{CPICH}$ power requires overcoming several challenges such as the coverage-capacity-quality tradeoff, ensuring adequate handover performance, controlling the amount of interference in the network and balancing the load among neighbor cells [8],[9].

A conventional strategy is to uniformly assign a constant proportion, typically $10-15 \%$, of the total cell power to $\mathrm{CPICH}$ [2]. Although convenient, this strategy may be inefficient in traffic varying cells. It has been shown in previous research that adopting non-uniform $\mathrm{CPICH}$ and optimizing its power setting can save CPICH power [3],[4] and balance cell load [7],[8]. Whereas power saving on CPICH may not be a crucial aspect to the power-controlled voice traffic, it is of great significance to data traffic. Moreover, reducing the $\mathrm{CPICH}$ power enables additional power saving on some of the other common control channels, of which the power is typically set in proportion to that of CPICH.

While setting the $\mathrm{CPICH}$ power level the first challenge we meet is a coverage-capacity tradeoff; this tradeoff rises such that the higher the $\mathrm{CPICH}$ power the bigger the coverage, while the lower the $\mathrm{CPICH}$ power allows more power to be used by traffic channels. For this project the $\mathrm{CPICH}$ power is optimized in such a way that the Cell coverage is reduced when a high cell load is detected by reducing the $\mathrm{CPICH}$ power. When a low load cell is detected the $\mathrm{CPICH}$ power is increased causing an increase in the Cell coverage hence ensuring the cell is well utilized.

Due to its significant impact on $3 \mathrm{G}$ cellular networks, $\mathrm{CPICH}$ power optimization has been the subject of various studies. In [5] for example, the authors presented a self-optimization based algorithm for tuning the CPICH pilot power which when running automatically, the algorithm can be used to autonomously control the pilot power and load balance traffic in the network and when scheduled or triggered manually, the algorithm can also be used to optimize the network capacity in clusters expecting a surge in during a certain time for example at a stadium during a match. The study in [10] presented a model and algorithm for antenna tilt and pilot power optimization for load balancing aimed at maximizing system capacity while [11] presented a rule-based parametric algorithm for common pilot channel and antenna tilt optimization in UMTS FDD Networks. While these studies provided a good foundation for this, they focused on the various mathematical approaches with no practical end to end completeness and the authors did not address challenges with efficiency and manual operations in their solutions.

\section{2) Frequency Spectrum and Frequency Reuse}

The available frequency spectrum is a crucial factor in determining the capacity of a $3 \mathrm{G}$ cellular system. To reduce the co-channel interference, second generation cellular networks like GSM (Global System for Mobile Communications) split the available frequency spectrum among the cells to have distinct frequencies in the adjacent cells. This allows the possibility of dynamic spectrum allocation to the cells to match the traffic dynamics. However, 3G cellular networks are frequency-re-use-1 systems, meaning they use the complete available spectrum in each cell, to increase the spectrum utilization [12]. Therefore in these networks, dynamic capacity enhancement in a cell by spectrum allocation is not a feasible solution.

\section{3) Base Station Density}

The densification of Base Transmitter Stations (BTS), such that the interference remains under a certain limit can provide significant gains in network coverage and capacity. However, BTSs cannot be deployed at arbitrary places. Due to legal obligations and cost, they can only be deployed at some carefully selected places. Moreover, financial and timing constrains also make this option feasible to cater for the long term coverage and capacity upgrades only.

\section{4) Sectorization}

The BTS coverage can be divided into multiple sectors using directional antennas [12]. Unlike Omni-directional antennas, directional antennas radiate the transmitted signals in a particular direction and therefore can increase the capacity of the network by reducing the interference in other directions. In traditional networks the number of sectors each BTS has, is decided at the planning phase. As it requires site visit and hardware upgrades to change the sectorization configuration, it can only be done over large periods of time.

\section{5) Antenna Azimuth}

Antenna azimuth is defined as the angle of main beam of a directional antenna w.r.t. the North Pole in the horizontal direction. It can be used to steer the antenna radiation pattern and to reduce the interference to the adjacent cells. If the adjacent antennas point towards each other they produce more interference compared to if they are directed away from each other. The value of azimuth is normally influenced by the relative positions of the adjacent $\mathrm{BS}$ and the targeted coverage areas. Therefore, the possibility of dynamic capacity enhancements by antenna azimuth adaptation are limited [13].

\section{6) Antenna Height}

Antenna height of the BSs also influences the received signal strengths in its coverage area. Higher the antenna height is, further the radio signals can propagate and therefore larger is the coverage area. However, its value is fixed at the planning phase and it is extremely difficult to modify it dynamically.

\section{7) Antenna Tilt}

Antenna tilt is defined as the elevation angle of the main lobe of the antenna radiation pattern relative to the horizontal plane. If the main lobe moves towards the earth it is known as downtilt and if it moves away it is known as uptilt. Higher antenna downtilts move the main lobe closer to the BTS and vice versa. Therefore, the antenna tilt value has a strong influence on the effective coverage area of the cell. Moreover, with relatively close direction of the main lobe to the BS the received signal strengths in own cell improves and the 
interference to neighboring cells reduces [14]. This improves the signal to interference plus noise (SINR) ratio for the mobile terminals and the network capacity increases. Therefore, antenna tilt can be used to alter both coverage and capacity of the network at the same time [15]-[17].

\section{8) Handover for load balancing}

In a cellular network, load balancing can also be performed by shifting traffic between neighboring cells. Handover (HO) is the process of transferring a call which is in progress from one channel to another. It consists of three main phases: measurement phase, decision phase and execution phase. By adjusting $\mathrm{HO}$ parameters settings, the size of a cell can be modified to send users from the current cell to neighboring cells $[18,19]$. Thus, the coverage area of the cell with high congestion can be reduced and that of neighboring cells take up traffic from the congested cell edge and as a result of a more even traffic distribution, the call blocking probability in the congested cell decreases [20]. Several studies in handover for load balancing have been done. In [21], a real time traffic balancing in cellular network by multi-criteria handoff algorithm using fuzzy logic for GERAN is presented. An algorithm to decide the balancing of the load between LTE, UMTS and GSM is presented in [22]. The load balancing and handover optimization functions may be used to improve the network performance and a conflict may arise when both functions attempt to adjust the same parameters at the same time. In [23] coordination algorithm of both functions is proposed with and aim to avoid the situation in which a parameter is simultaneously increased by both functions, achieving extreme values that may negatively affect network performance.

\section{METHODOLOGY}

A fuzzy logic controller was designed and simulated in Mat lab. The FLC was involved in the detection of high load $3 \mathrm{G}$ cells that do not have enough cell resources available and could benefit from $\mathrm{CPICH}$ power adjustment as a radio optimization engineer would normally do manually. The FLC was designed with 3 inputs which are the downlink cell load, received total wideband power (RTWP) and the neighboring cells' load. The output of the FLC was the CPICH power setting which would determine whether to increase or decrease the coverage footprint of the cell hence influencing the cell downlink power utilization.

\section{Downlink Cell Load}

The downlink cell capacity is limited by its total available transmit cell power, which is determined by the NodeB RF module capability and the maximum output power configured for the cell. The proportion between voice and data traffic varies all the time. The capacity left over from Voice traffic is reserved for the best effort data traffic. The overall goal is to provide as much capacity as possible to the users.

The downlink transmit power consists of the following, as shown in fig. 1:

1. Common channel $(\mathrm{CCH})$ power

2. Non- high speed packet access (HSPA) power-Voice

3. HSPA power-Data traffic

4. Power margin

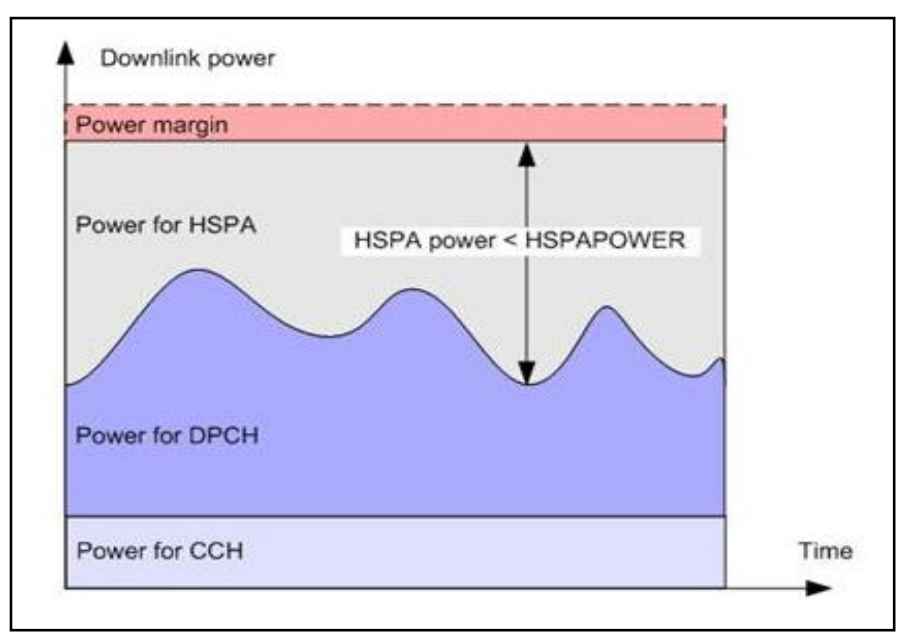

Fig. 1. Dynamic power resource allocation

Downlink power resources are allocated as follows:

1. Downlink power resources are first reserved for Common Control physical channels and allocated to the Dedicated Physical Channel. The remaining power resources are available for Data traffic.

2. The Data power resources are first allocated to the high speed uplink packet access (HSUPA) downlink control channels while the remaining power resources are allocated for high speed downlink packet access (HSDPA).

3. The HSDPA power resources are first allocated to the downlink control channel high-speed shared control channel (HS-SCCH) while the remaining power resources are allocated for the traffic channel high-speed physical downlink shared channel (HS-PDSCH).

Downlink power consumption is related to cell coverage, user equipment (UE) locations, and the traffic load in the cell. Large cell coverage, UEs being physically far away from the cell center, and heavy traffic load all contribute to large downlink power consumption. Therefore, downlink power overload is more likely to occur in hotspots or in cells with large coverage.

When the Downlink transmit power is insufficient, the following occurs:

1. The data throughput decreases.

2. The service quality declines.

3. New user service requests are likely to be rejected.

\section{Uplink Interference (RTWP)}

The WCDMA system is limited by interference (the less interference there is, the more capacity the system can offer to the users). Every user equipment (UE) accessing the network generates a signal which, from the point of view of the base transceiver station (BTS), increases interference in the system. At the same time, the capacity of a WCDMA system is proportional to the level of interference in the system. The less interference there is, the more capacity the system can offer. The relationship between the rise over thermal (RoT) and the uplink load factor is as indicated in fig. 2 below: 


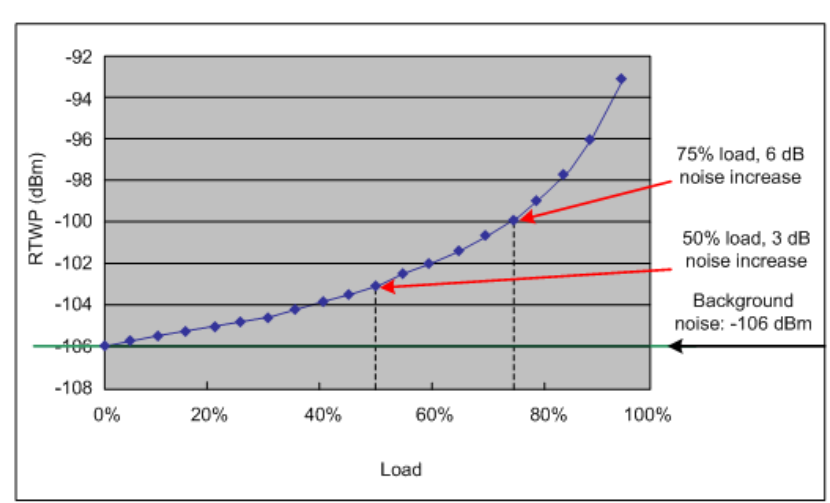

Fig. 2. Relationship between RTWP, noise increase, and uplink load

\section{E. Neighbour cells' load}

The Neighbor cells' load as shown in fig 3 below; is factored so as to prevent traffic steering to high loaded cells and the pilot power adjustment is not adjusted when neighbor cell is already overloaded. As illustrated below the serving cell is highly loaded same applies to the neighboring cells. Therefore in this case it wouldn't be advisable to ramp down the CPICH power of the current serving cell as the traffic would be offloaded to an already overloaded cell therefore negatively impacting further on the cell quality.

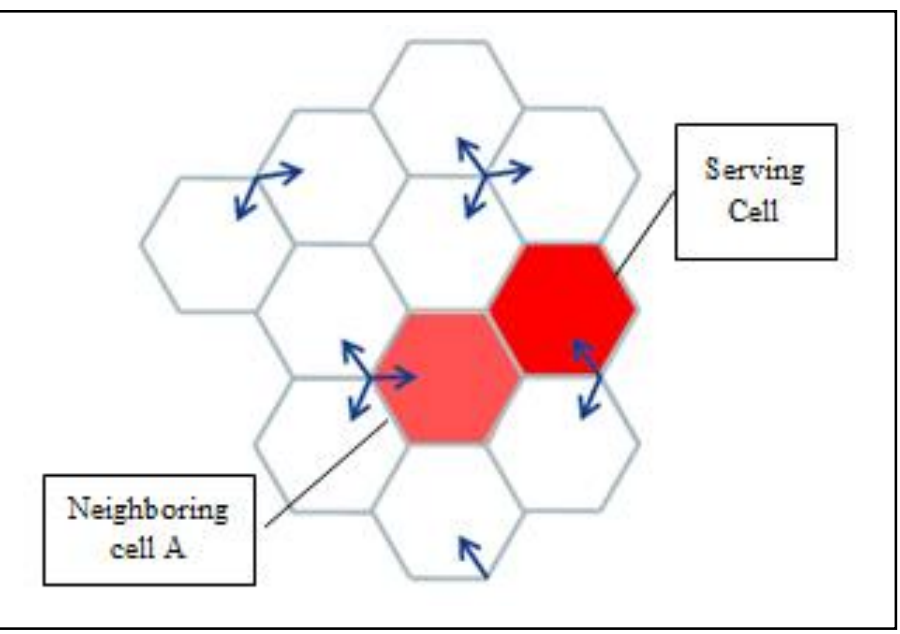

Fig. 3. Neighbor cells' load

A 3G network cell was identified (Cell A) whose Downlink Cell Load and Call Setup Success Rate are as shown in fig 4 below. As the cell load increases, the quality of the cell degrades and it has poor call set up success rate. The Overall goal is to balance the load between neighboring cells therefore improving the performance of the cell with congestion issues. Fig. 5 below shows the Hourly Downlink Cell load for two neighboring cells $\mathrm{A}$ and $\mathrm{B}$. It can be seen that Cell A has so much load especially in the busy hour as compared to cell B. Therefore, Cell A load can be relieved by handing over some of its traffic to Cell B.

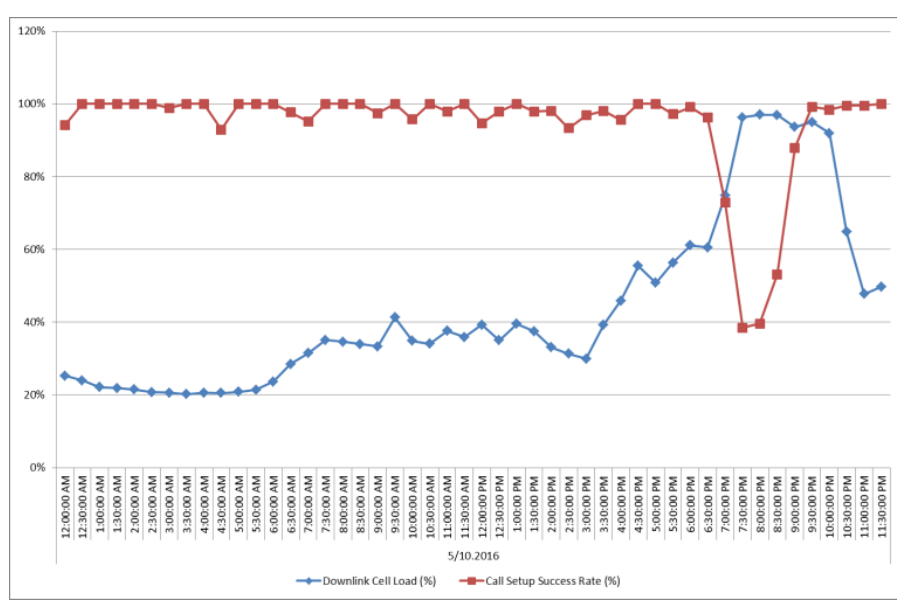

Fig. 4. Hourly Downlink Cell Load and Call Setup Success Rate for Cell A

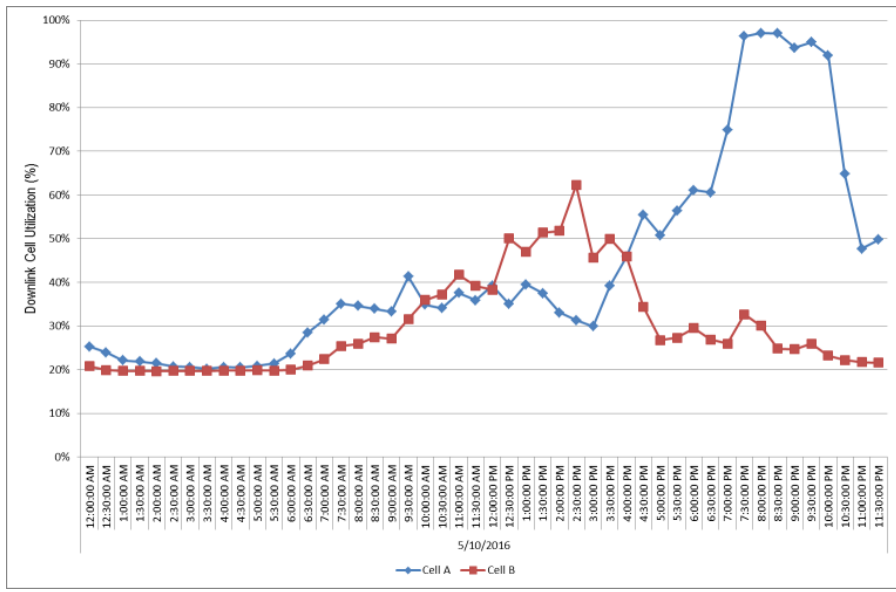

Fig. 5. Hourly Downlink Cell Utilization for Cell A and Cell B

Increasing pilot power makes the cell bigger while reducing pilot power makes the cell smaller. Therefore, pilot power can be used as a tool for traffic load balancing among cells. For this study we shall consider a network of six cells as in Fig. 6. Cells before pilot power adjustment are as shown. The cell experiencing excessive load is represented in red color while green cells represent cells with normal load. The intersection between the red and green cell on Fig. 6(a) represents an area which is receiving pilot power greater or equal to a given threshold from more than one cell. Fig. 6(b) shows the cells after pilot power adjustment on cell A during which the $\mathrm{CPICH}$ power is reduced and hence reducing the cell coverage. The yellow cells represent load after redistribution.

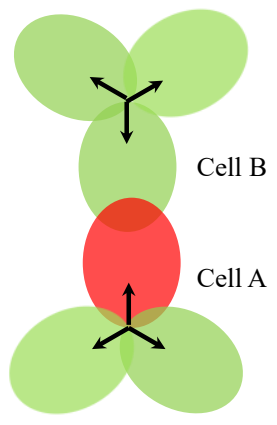

(a)

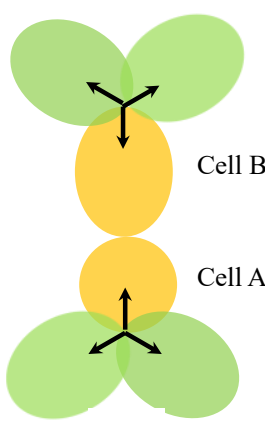

(b)
Fig. 6. Network cells with different cell loading 


\section{DEVELOPMENT OF FUZZY LOGIC CONTROLLER FOR CPICH POWER OPTIMIZATION}

The CPICH power of a cell was controlled based on Fuzzy rules based on the downlink cell utilization. First a FLC was designed on Mat lab with 3 inputs which are the Downlink cell load, Received Total Wideband Power (RTWP); Interference in the cell and the neighboring cells' load. The output of the FLC will be the CPICH power setting which will determine whether to increase or decrease the coverage footprint of the cell hence influencing the cell DL power utilization. Secondly the effect of varying the CPICH power on the downlink cell utilization based on fuzzy logic was investigated. The proposed FLC based cell capacity enhancement approach was then evaluated through a comparison with a cell with constant proportion $\mathrm{CPICH}$ power. It was expected that the cell would be utilized better with FLC in place as would be shown by the Key Performance Indicator (KPI) monitoring tool. There were also expected gains on the data speeds in bits/sec at peak hours of the day.

In the proposed algorithm the range of the Downlink cell load is taken to be $0 \%$ to $100 \%$, the RTWP varies from $-110 \mathrm{dBm}$ to $-70 \mathrm{dBm}$ and the neighboring cells' load ranges from $0 \%$ to $100 \%$. The $\mathrm{CPICH}$ power setting was from $30 \mathrm{dBm}$ to $36 \mathrm{dBm}$. For system simulation Mamdani Fuzzy Inference system was used due to fact that the method is well suited to human input and the nature of wireless networks is nonlinear. Fuzzy inference gathers the input values of Downlink Cell Load, Uplink Interference and Neighbor cells' load fuzzy set as crisp inputs and then evaluates them according to the fuzzy rules base. The composed and aggregated output of rules evaluation was defuzzified using the centroid of area method and crisp output is obtained.

The input linguistic variables were chosen as in Table 1 to Table 3 below:

Table 1: Downlink Cell Load fuzzy set

\begin{tabular}{|l|l|}
\hline Fuzzy set or label & Set Description \\
\hline $\begin{array}{l}\text { VLL: Very Low } \\
\text { Load }\end{array}$ & $\begin{array}{l}\text { The load is very low as compared to the desired } \\
\text { value }\end{array}$ \\
\hline $\begin{array}{l}\text { MLL: Medium Low } \\
\text { Load }\end{array}$ & The load is low but close to the desired value \\
\hline NL: Normal Load & The load is in the normal range \\
\hline $\begin{array}{l}\text { MHL: Medium High } \\
\text { Load }\end{array}$ & The load is high but close to the desired value \\
\hline $\begin{array}{l}\text { VHL: Very High } \\
\text { Load }\end{array}$ & $\begin{array}{l}\text { The load is very high as compared to the desired } \\
\text { value }\end{array}$ \\
\hline
\end{tabular}

Table 2: Uplink Interference fuzzy set

\begin{tabular}{|l|l|}
\hline Fuzzy set or label & Set Description \\
\hline $\begin{array}{l}\text { VWI: Very Weak } \\
\text { Interference }\end{array}$ & The cell has very weak interference \\
\hline $\begin{array}{l}\text { MWI: Medium Weak } \\
\text { Interference }\end{array}$ & The cell has medium weak interference \\
\hline ZI: Zero Interference & $\begin{array}{l}\text { The cell interference is within the } \\
\text { acceptable levels }\end{array}$ \\
\hline $\begin{array}{l}\text { MSI: Medium Strong } \\
\text { Interference }\end{array}$ & The cell has medium strong interference \\
\hline $\begin{array}{l}\text { VSI: Very Strong } \\
\text { Interference }\end{array}$ & $\begin{array}{l}\text { The cell has very strong interference (very } \\
\text { poor quality) }\end{array}$ \\
\hline
\end{tabular}

Table 3: Neighbor cells' load fuzzy set

\begin{tabular}{|l|l|}
\hline Fuzzy set or label & Set Description \\
\hline $\begin{array}{l}\text { NLL: Neighbour Low } \\
\text { Load }\end{array}$ & $\begin{array}{l}\text { The Neighbor cells' load is very low as } \\
\text { compared to the desired value }\end{array}$ \\
\hline $\begin{array}{l}\text { NNL: Neighbour } \\
\text { Normal Load }\end{array}$ & $\begin{array}{l}\text { The Neighbor cells' load is in the normal } \\
\text { range }\end{array}$ \\
\hline $\begin{array}{l}\text { NHL: Neighbour High } \\
\text { Load }\end{array}$ & $\begin{array}{l}\text { The Neighbor cells' load is very high as } \\
\text { compared to the desired value }\end{array}$ \\
\hline
\end{tabular}

The output linguistic variables are given Table 3-4 below:

Table 4: CPICH Power fuzzy set

\begin{tabular}{|l|l|}
\hline Fuzzy set or label & Set Description \\
\hline $\begin{array}{l}\text { NLC: Negative Large } \\
\text { CPICH Power }\end{array}$ & $\begin{array}{l}\text { CPICH power to be large in the negative } \\
\text { direction }\end{array}$ \\
\hline $\begin{array}{l}\text { NSC: Negative Small } \\
\text { CPICH Power }\end{array}$ & $\begin{array}{l}\text { CPICH power to be small in the negative } \\
\text { direction }\end{array}$ \\
\hline ZC: Zero CPICH Power & $\begin{array}{l}\text { CPICH power to be around the normal } \\
\text { value }\end{array}$ \\
\hline $\begin{array}{l}\text { PSC: Positive Small } \\
\text { CPICH Power }\end{array}$ & $\begin{array}{l}\text { CPICH power to be small in the positive } \\
\text { direction }\end{array}$ \\
\hline $\begin{array}{l}\text { PLC: Positive Large } \\
\text { CPICH Power }\end{array}$ & $\begin{array}{l}\text { CPICH power to be large in the positive } \\
\text { direction }\end{array}$ \\
\hline
\end{tabular}

Fig. 7 to 10 show the fuzzy input variable for Downlink cell load, RTWP, the neighboring cells' load and CPICH power setting respectively. Each of the fuzzy input variables has subsets which are mapped to the corresponding membership functions. The membership functions define how each point in the input space is mapped to a membership value between 0 and 1. The Gaussian type membership function was chosen for the inputs and outputs because it represents the nonlinear nature of the problem in a better way than triangular or trapezoidal membership functions. Furthermore, the triangular and trapezoidal membership functions contain discontinuities in their derivatives, which can result in abrupt changes in the output of the controller. The membership functions for the downlink cell load and uplink interference were made denser at the center in order to provide more sensitivity. 75 IF-THEN rules provide knowledge to the system and decide whether to increase or decrease the output CPICH power of the cell. These rules very much resemble the human thought process, thereby providing artificial intelligence to the system.

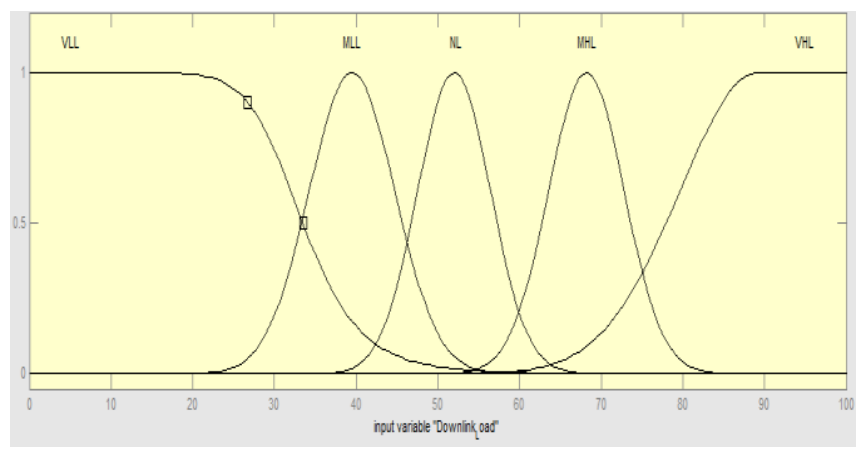

Fig. 7. Membership function for Downlink cell load 


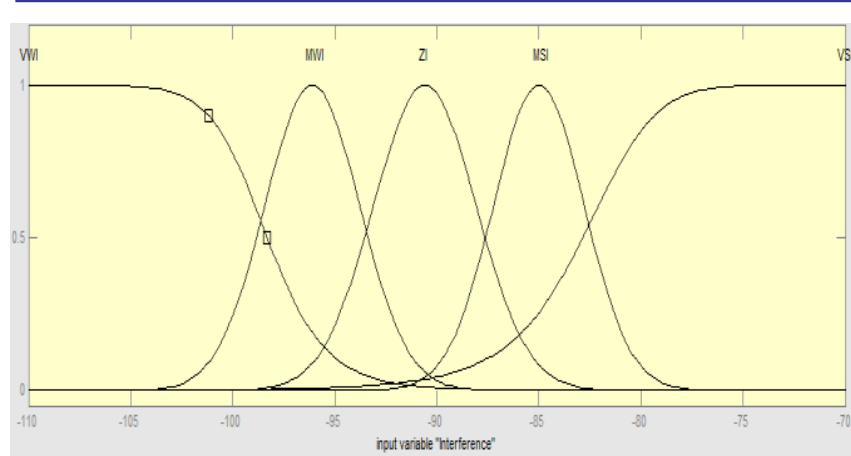

Fig. 8. Membership function for RTWP (Interference in the cell)

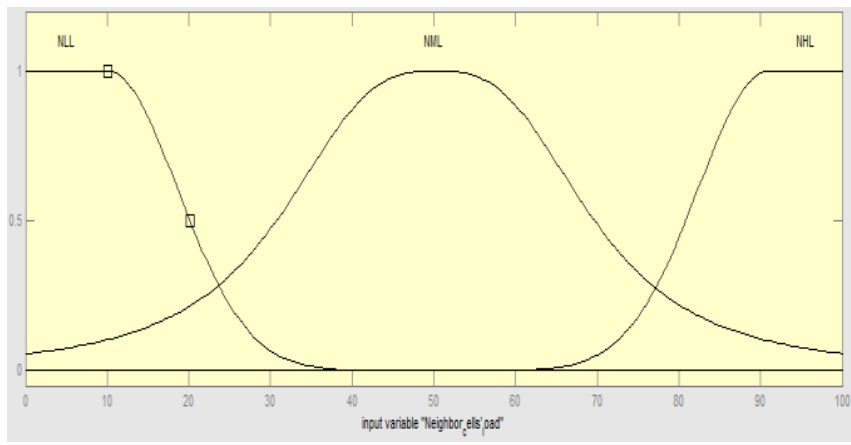

Fig. 9. Membership function for neighboring cells' load

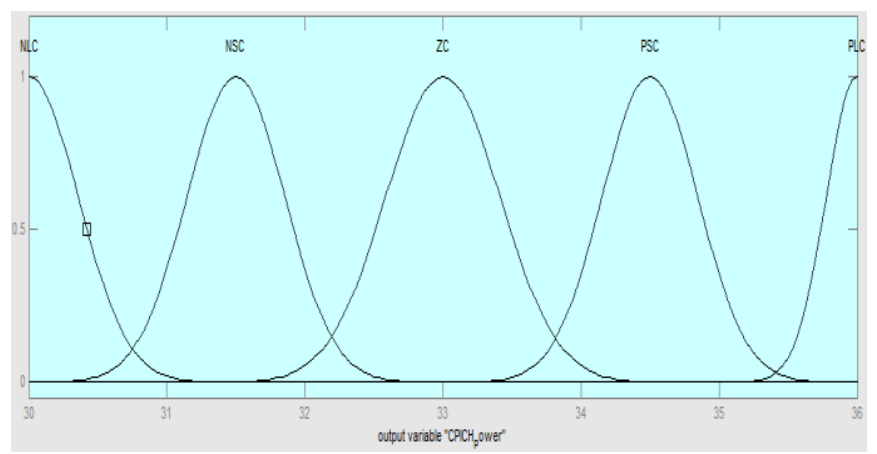

Fig. 10. Membership function for $\mathrm{CPICH}$ power setting

An example of the of the IF-THEN rules include;

1. If Downlink Load is VLL and interference is VWI and Neighbour cells' load is NLL then CPICH power is PLC

2. If Downlink Load is VLL and interference is MWI and Neighbour cells' load is NLL then CPICH power is PLC

3. If Downlink Load is VLL and interference is ZI and Neighbour cells' load is NLL then CPICH power is PLC

\section{RESULTS AND DISCUSSION}

In the network scenario, we used 2 base stations with 3 -sector antennas thus comprising 6 cells. The calculation for the Downlink cell load without fuzzy at any time $i$ in percentage $\left(D_{U t i l}^{i}(\%)\right)$ will be given by the equation below;

$D_{U t i l}^{i}(\%)=\frac{10^{\left(P_{U t i l}^{i}(d B m) / 10\right)} / 1000}{10^{(43) / 10)} / 1000} \times 100$
The constant $\mathrm{CPICH}$ power $P_{C P I C H}(\mathrm{dBm})$ for the cell is $33 \mathrm{dBm}$. The power conversion of $\mathrm{dBm}$ to watts is given by the formula:

$$
P_{C P I C H}(W)=1 W \cdot 10^{\left(P_{C P I C H}(d B m) / 10\right)} / 1000
$$

The calculation for the Downlink cell load with fuzzy at any time $i$ in percentage $\left(D_{\text {Fuzzy Util }}^{i}(\%)\right)$ will be given by the equation below;

$$
\begin{aligned}
D_{\text {Fuzzy Util }}^{i}(\%)= & \left\{\left(D_{\text {Util }}^{i}(\%)-10\right)\right. \\
& \left.\times \frac{10^{(\text {Fuzzy CPICH }(d B m) / 10)} / 1000}{10^{(33) / 10)} / 1000}\right\} \\
& +\left\{\frac{10^{(\text {Fuzzy CPICH }(d B m) / 10)} / 1000}{10^{(43) / 10)} / 1000}\right. \\
& \times 100\}
\end{aligned}
$$

Where $D_{U t i l}^{i}(\%)$ is the Downlink cell load and Fuzzy CPICH $(\mathrm{dBm})$ is the output of the Fuzzy logic controller

\section{F. Effect of varying the CPICH power on the downlink cell utilization}

Fig. 11. below shows the normal utilization trend of a cell with a constant $\mathrm{CPICH}$ power assigned. It can be seen that the $\mathrm{CPICH}$ power is constant at $33 \mathrm{dBm}$, that is, $10 \%$ of the total downlink cell power. The downlink cell utilization varies throughout the day depending on the traffic. As seen from the figure in the wee hours of the night i.e. $4 \mathrm{am}$ the cell utilization is very low at $20 \%$. As the day progresses, the downlink cell utilization increases and at $9 \mathrm{pm}$ the cell utilization is at the highest at $96 \%$. As stated before this will have an impact on the data throughput as the data only utilizes the remaining power on sharing mode among all the users. It therefore shows that there is a need for better utilization of the cell.

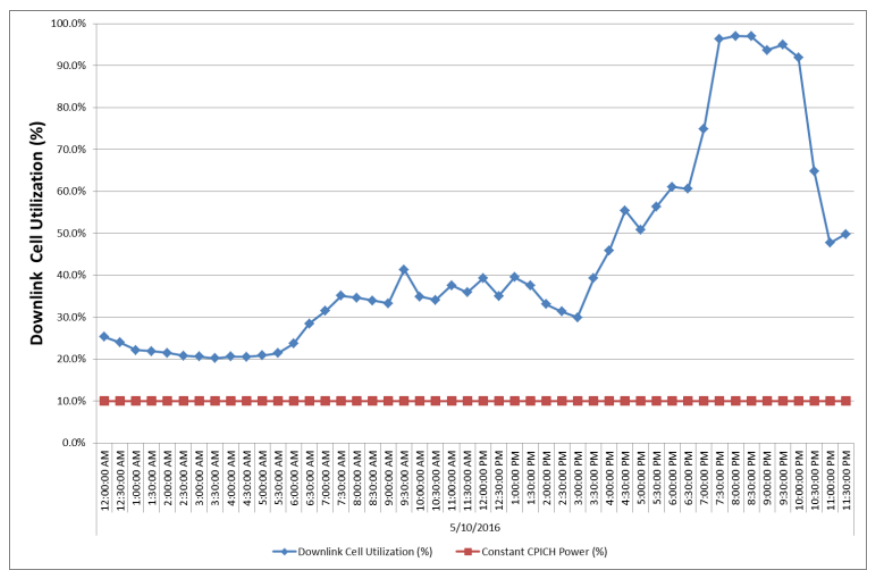

Fig. 11. Normal Downlink Cell Utilization and $\mathrm{CPICH}$ power

Where $P_{U t i l}^{i}(\mathrm{dBm})$ is the Cell Utilization in $\mathrm{dBm}$. 


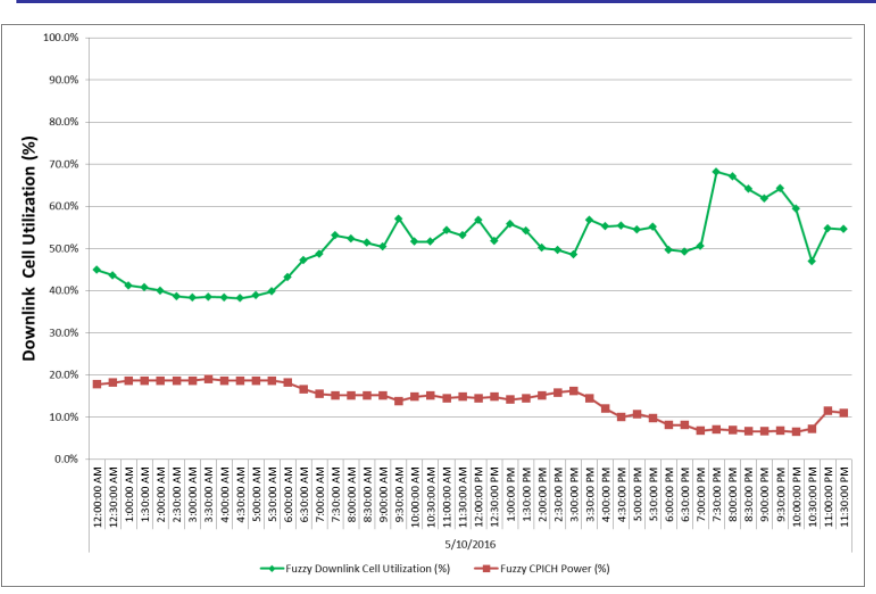

Fig. 12. Fuzzy logic optimized Downlink cell utilization and $\mathrm{CPICH}$ power

Fig. 12 above shows the Downlink cell utilization trend of a cell after fuzzy logic has been applied to vary the $\mathrm{CPICH}$ power. In this case the $\mathrm{CPICH}$ power is no longer constant at $33 \mathrm{dBm}$ but varied from a high of $36 \mathrm{dBm}$, that is, $20 \%$ of the total cell power to a low of $30 \mathrm{dBm}$, that is, $5 \%$ of the cell power. Also the cell load utilization is seen to be better as the wee hours of the night carry more traffic than before as the $\mathrm{CPICH}$ power was increased, hence increasing the cell coverage footprint and the cell traffic. Better data speeds at the busy hour are achieved as the cell utilization is now lower.

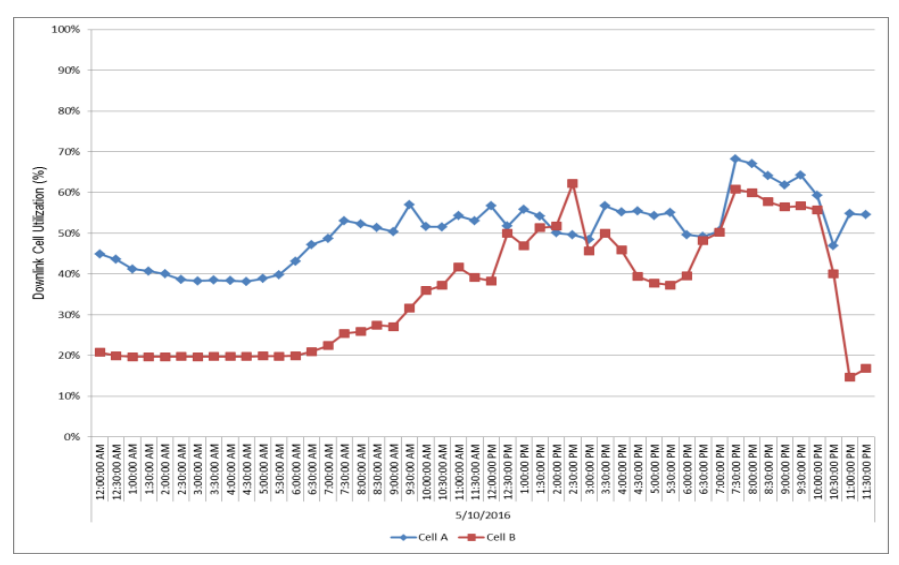

Fig. 13. Hourly Downlink Cell Utilization for Cell A and Cell B after CPICH power control using fuzzy logic

Fig. 13 above shows the hourly downlink cell utilization for cell A and cell B after the $\mathrm{CPICH}$ pilot power adjustment of cell A was done using fuzzy logic. The adjustment of the $\mathrm{CPICH}$ pilot power in cell A especially in the busy hours when the cell has excessive load resulted in the excessive traffic being steered to cell $\mathrm{B}$ which has less traffic during that time.

Therefore it can be concluded that the tuning of the $\mathrm{CPICH}$ power has a great impact on the downlink cell utilization largely due to the impact the tuning of the $\mathrm{CPICH}$ power has on the cell coverage area. Fuzzy logic control was successfully used to automatically control the CPICH power and improved the downlink cell load. In addition it was found that the CPICH power tuning has a large impact on the downlink cell utilization and it can be used to mitigate the load imbalance between neighbouring cells by changing the coverage area of the cells.

\section{G. Evaluation of the CPICH Power optimization based on Fuzzy Logic Controller}

The evaluation of the performance of the $\mathrm{CPICH}$ power control system based on fuzzy logic was done through 2 metrics. These were the cell's call setup success rate (CSSR) and finally a comparison of the downlink cell utilization with and without fuzzy control was done.

Fig 14 below shows the call setup success rate (CSSR) trend before and after the CPICH pilot power control using fuzzy logic. There was a great improvement especially in the peak hours when there was a dip as below as $38.5 \%$ previously improving to $88.5 \%$. This indicates over $100 \%$ improvement in this KPI during the peak hour.

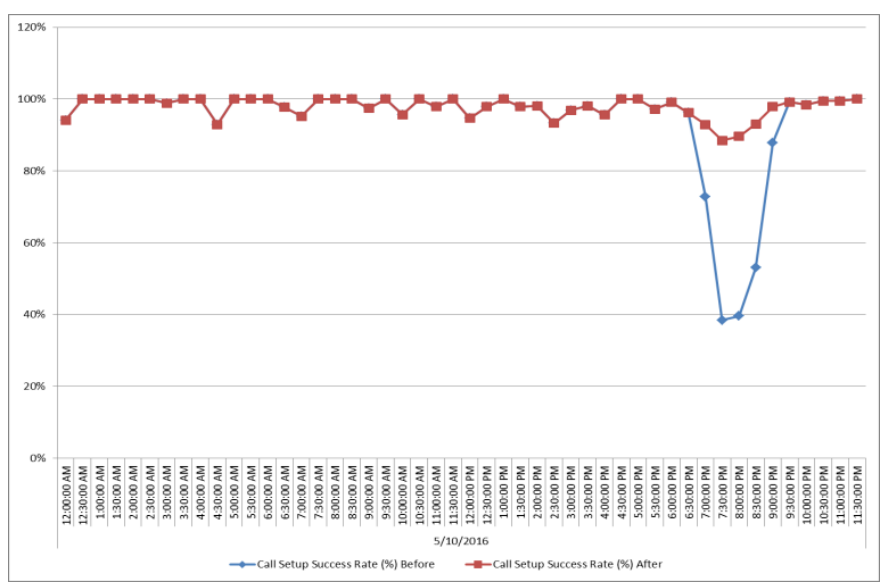

Fig. 14. Comparison of the Downlink Cell load with and without fuzzy logic control

Fig. 15 below shows the comparison of the Downlink cell utilization trend of a cell with and without fuzzy logic control being applied to vary the $\mathrm{CPICH}$ power. It can be seen that the Downlink cell utilization with fuzzy is better that without fuzzy. In the off peak hours of the day, that is, from midnight to mid-day the cell without fuzzy was very low utilized but after the application of fuzzy logic control the traffic increased and the cell is more efficiently utilized. In the peak hours of the day, that if, between $7 \mathrm{pm}$ and 10pm the cell was over utilized resulting to poor experience but after fuzzy logic is applied the cell has optimal utilization after the decrease in the CPICH power resulting to a lower traffic.

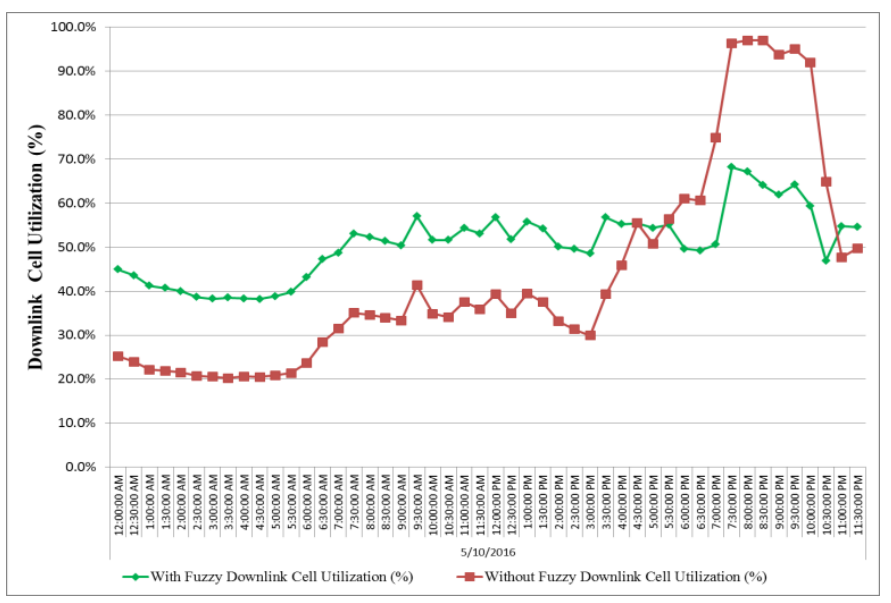

Fig. 15. Comparison of the Downlink Cell load with and without fuzzy logic control 


\section{CONCLUSION AND FUTURE WORK}

We demonstrated a CPICH power control algorithm for $3 \mathrm{G}$ cellular networks for cell capacity based on fuzzy logic control. Through Fuzzy Logic Control, the developed algorithm addresses the challenge of increasing complexity of manually optimizing the ever growing and dynamically changing traffic patterns of a $3 \mathrm{G}$ network. The developed algorithm can be used to autonomously optimize CPICH power and balance traffic load in the network, for example in the case of a traffic surge due to an accident or an event happening at a location. Simulation results show that the CPICH power control based on fuzzy process achieves a significant improvement in the Downlink cell utilization which in turn improves the cell performance.

The current study was limited to 2 neighboring base stations; further research can be done to include a number of cells in a cluster. In addition further work should be done with regards to investigating the impact of the $\mathrm{CPICH}$ power optimization based on Fuzzy logic on the cell data throughputs.

\section{REFERENCES}

[1] C. Johnson, "Radio Access Networks For UMTS; Principles and Practice", John Wiley \& Sons, 2008.

[2] H. Holma, A. Toskala, "WCDMA for UMTS Radio Access for Third Generation Mobile Communication", John Wiley \& Sons, 2000

[3] M. N. Islam, R. Abou-Jaoude, C. Hartmann, A. Mitschele-Thiel, "Self Optimization of Antenna Tilt and Pilot Power for dedicated channels", Proceedings of the 8th International Symposium on Modeling and Optimization in Mobile, Ad Hoc and Wireless Networks (WiOpt), June 4 2010 pp. 196,203, 2010.

[4] L. Chen, D. Yuan, "CPICH power planning for optimizing HSDPA and R99 SHO performance: Mathematical modelling and solution approach", Wireless Days 2008. WD '08. 1st IFIP, pp. 1, Nov. 2008.

[5] H. Mfula, T. Isotalo, J. Nurminen, "Self-optimization of power parameters in WCDMA networks", High Performance Computing \& Simulation (HPCS) 2015 International Conference on, pp. 80-87, 2015.

[6] F. Karray and C. De Silva, "Soft computing and tools of intelligent systems design". Harlow: Addison-Wesley, 2004

[7] J. Sánchez-González, J. Pérez-Romero and O. Sallent, "A Rule-Based Solution Search Methodology for Self-Optimization in Cellular Networks", Communications Letters IEEE, vol. 18, pp. 2189-2192, 2014, ISSN 1089-7798.

[8] I. Siomina, P. V“arbrand, and D. Yuan, "Pilot power optimization and coverage control in WCDMA mobile networks", Omega, 35 pp. 683696, 2007.
[9] I. Siomina and D. Yuan. Minimum, "Pilot power for service coverage in WCDMA networks", Wireless Networks, 14, pp. 393-402, 2008

[10] M. N. Islam, R. Abou-Jaoude, C. Hartmann, A. Mitschele-Thiel, "Self Optimization of Antenna Tilt and Pilot Power for dedicated channels", Proceedings of the 8th International Symposium on Modeling and Optimization in Mobile, Ad Hoc and Wireless Networks (WiOpt), June 4 2010, pp.196,203, 2010.

[11] A. Gerdenitsch, S. Jakl, Y. Y. Chong, M. Toeltsch. A Rule-Based Algorithm for Common Pilot Channel and Antenna Tilt Optimization in UMTS FDD Networks , ETRI Journal, Vol. 26, Issue 5, pp. 437-442, Oct. 2004.

[12] M. Terré, M. Pischella and E. Vivier, Wireless telecommunication systems. Hoboken: Wiley, 2013.

[13] Okumuş H.İ., Şahin E., Akyazi Ö., "Antenna Azimuth Position Control With Fuzzy Logic And Self-Tuning Fuzzy Logic Controllers", 8th International Conference on Electrical and Electronics Engineering, ELECO 2013, pp.477-481

[14] D. W. Kifle, B. Wegmann, I. Viering, A. Klein, "Impact of antenna tilting on propagation shadowing model", 2013 IEEE 77th Vehicular Technology Conference (VTC Spring), pp. 1-5, June 2013.

[15] B. Yu, L. Yang, H. Ishii, X. Cheng, " Load Balancing with Antenna Tilt Control in Enhanced Local Area Architecture", 2014 IEEE 79th Vehicular Technology Conference (VTC Spring), pp. 1-6, 2014

[16] K. Toda, T. Yamamoto, T. Ohseki, S. Konishi, " Load Balancing Techniques Based on Antenna Tilt and Handover Timing Control", Vehicular Technology Conference (VTC Fall), 2013 IEEE $78^{\text {th }}$, pp. 1-6, 2013

[17] I. Forkel, A. Kemper, R. Pabst, R. Hermans "The effect of electrical and mechanical antenna down-tilting in UMTS networks" , $3 G$ Mobile Communication Technologies, 2002. Third International Conference on (Conf. Publ. No. 489), pp 86 - 90, 2002

[18] P. Muñoz, R. Barco, I. de la Bandera, "Optimization of load balancing using fuzzy Q-Learning for next generation wireless networks", Expert Syst. Appl., vol. 40, no. 4, pp. 984-994, Mar. 2013.

[19] P. Muñoz, R. Barco, I. Bandera, "On the Potential of Handover Parameter Optimization for Self-Organizing Networks", Vehicular Technology IEEE Transactions on, vol. 62, pp. 1895-1905, 2013.

[20] W. Adnan; R. Rahman; M.Ibrahim, M. Kassim, "Performance evaluation of soft handover parameters in WCDMA system", Instrumentation Control and Automation (ICA), 2011 2nd International Conference on, pp $246-251$, Feb. 2011.

[21] P. Munoz, R. Barco, I. De la Bandera, M. Toril, and S. Luna-Ramfrez, "Optimization of a fuzzy logic controller for handover-based load balancing," in Proc. IEEE 73rd IEEE Vehicular Technology Conference (VTC), May 2012

[22] H M ElBadawy, "Optimal RAT selection algorithm through Common Radio Resource Management in heterogeneous wireless networks", Radio Science Conference (NRSC) 2011 28th National, pp. 1-9, 2011.

[23] P. Munoz, R. Barco, S. Fortes, "Conflict resolution between load balancing and handover optimization in LTE networks", IEEE Commun. Lett., vol. 18, no. 10, pp. 1795-1798, Oct. 2014 